\title{
DE LA OCUPACIÓN ROMANA EN AD PONTEM: EVIDENCIAS DE LAS OBRAS DEL TRANVÍA METROPOLITANO JUNTO AL CASTILLO DE SAN ROMUALDO (SAN FERNANDO, CÁDIZ)
}

\section{EVIDENCE OF THE ROMAN OCCUPATION IN AD PONTEM: STUDY OF THE REMAINS FOUND DURING CONSTRUCTION OF THE METROPOLITAN TRAM NEAR TO THE CASTLE OF SAN ROMUALDO (SAN FERNANDO, CÁDIZ)}

\section{José J. DÍAZ RODRÍGUEZ ${ }^{1 *}$, Darío BERNAL-CASASOLA ${ }^{1 * *}$ y María Luisa LAVADo FLORIDO ${ }^{2 * * *}$}

${ }^{1}$ Dpto. de Historia, Geografía y Filosofía, Universidad de Cádiz, Avda. Dr. Gómez Ulla 1, 11001, Cádiz

${ }^{2}$ Arqueóloga

* Correo electrónico: josejuan.diaz@uca.es

** Correo electrónico: dario.bernal@uca.es

***Correo electrónico: marialuisa_lavado@hotmail.com

Resumen: Se presentan los resultados del estudio de dos espacios de época romana de funcionalidad diversa documentados durante las obras de construcción del tranvía metropolitano de la bahía de Cádiz a su paso por San Fernando, ubicados en el entorno del Castillo de San Romualdo. Por un lado, se ha podido atestiguar la presencia de un nuevo taller alfarero de época altoimperial, gracias a la documentación de un vertedero cerámico. Por otro, las subestructuras de un pequeño balneum que quizás evidencie la presencia de un lugar de hábitat doméstico en la zona.

Palabras Clave: Arqueología preventiva, San Fernando, Ad Pontem, alfarería, balneum.

Abstract: In this paper, we show the results of the study of two Roman sites found during the construction of the Metropolitan Tram of the Bay of Cádiz, located in the surroundings of the Castillo de San Romualdo in San Fernando (Cádiz). One of them it is a pottery dump of a new figlina and the other corresponds to two rooms of a balneum whose hypocausis has been preserved.

Keywords: Rescue excavation, San Fernando, Ad Pontem, pottery workshop, balneum.

Sumario: 1. Introducción. 2. Vestigios de actividades alfareras. 3. El balneum de la plaza Font de Mora. 4. Valoración general de los hallazgos. 5. Agradecimientos. 6. Bibliografía.

\section{A Antonio Sáez Espligares, alma mater y guardián de la Arqueología isleña.}

\section{Introducción}

Con motivo de la ejecución de las obras del tramo II del proyecto del tren - tranvía metropolitano de la bahía de Cádiz, entre finales del año 2008 y el comienzo del año 2010 se desarrolló una actividad arqueológica preventiva en el término municipal de San Fernando que estuvo dirigida por M ${ }^{\mathrm{a}}$ Luisa Lavado. Los trabajos consistieron en el control arqueológico de los importantes movimientos de tierras que esta obra llevó aparejados, así como la excavación puntual en los yacimientos que se vieron afectados por la misma en los más de cin- co kilómetros del trazado entre el caño Zurraque y el entronque del trazado tranviario con la línea de ferrocarril en la zona de la Ardila (Lavado, 2011).

El trazado de la obra se desarrolló por el centro de la ciudad, remodelando la c/ Real, que es la principal arteria de San Fernando y sucesora del antiguo camino del arrecife en buena parte de su trazado. La afección de la obra provocó la documentación de importantes vestigios, fundamentalmente de época moderna y contemporánea inicial, como restos de los muros de delimitación del antiguo camino (Figura 1a), pavimentaciones de bolos de la antigua c/ Real (Figura 1b), conducciones subterráneas (Figura 1c y d), pozos y fosas de vertidos. Asimismo, en el entorno del Puente Zuazo se hallaron restos constructivos conocidos gracias 

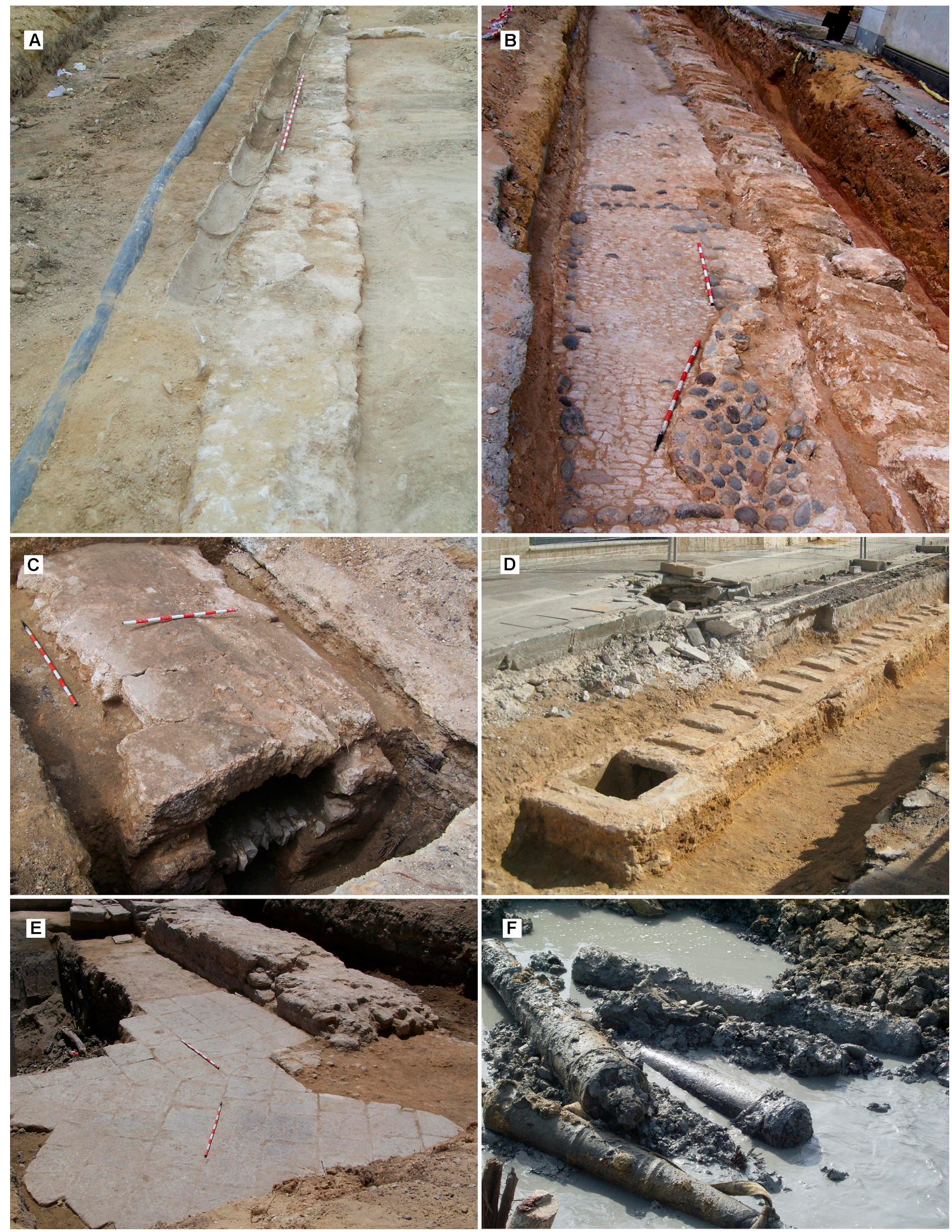

Figura 1. Restos de época moderna documentados durante la intervención arqueológica a su paso por San Fernando. a) Muro de cierre longitudinal del Camino del Arrecife; b) pavimento de bolos en c/ Real; c) registro del sistema de alcantarillado; d) tramo del alcantarillado; e) solería de una de las baterías anejas al Castillo de San Romualdo; f) algunos de los cañones localizados en el fango. 
a la cartografía histórica, pero cubiertos hasta entonces por la sedimentación de fangos, vinculados al complejo de baterías defensivas que lo custodiaban (Figura 1e), así como un total de diecisiete cañones de hierro (Figura 1f), que quizás quedaron enterrados tras la contienda bélica contra los franceses en los asedios acaecidos a comienzos del s. XIX. De época prerromana fue interesante la documentación de un horno cerámico datado entre los ss. V-III a.C. y sus correspondientes áreas de vertidos (Lavado y Sáez, 2009). Por último, de época romana se localizaron de forma dispersa diversos materiales cerámicos en algunos tramos de la obra, como por ejemplo en la plaza del Carmen, en la Alameda Moreno de Guerra o en el entorno del acceso al puente Zuazo -quizás parte de la antigua vía romana-. Sin embargo, lo más destacado fue la documentación de los restos de un asentamiento villático con varias estancias localizado en la zona de la Ardila (Figura 2a), en las inmediaciones de la Fuente Tusquets, así como un conjunto de estructuras y bolsadas de materiales documentadas en el trazado de la obra desde la Venta de Vargas hasta la Plaza Font de Mora, en el entorno del Castillo de San Romualdo (Figura 2b). Sobre estas últimas evidencias desarrollaremos este trabajo.

\section{Vestigios de actividades alfareras}

Durante el control arqueológico de una de las zanjas de servicio abiertas en la zona coincidente con la antigua mediana que desembocaba desde la c/ Real con la antigua rotonda de la Venta de Vargas, entre los PPKK 2+909 y 2+912 del trazado del tranvía, se documentó una bolsada de cerámicas de época romana que, por sus características, debemos asociar con el área de vertido de desechos cerámicos de un taller alfarero romano. La zanja, de aproximadamente un metro de anchura, atravesó una zona ajardinada. Tras retirar los niveles contemporáneos asociados a la tierra vegetal del parterre y la subbase del mismo, se individualizó un estrato que presentaba gran cantidad de fragmentos cerámicos, escorias y adobes defectuosos. Se trata de un nivel sedimentario de aproximadamente unos $60 \mathrm{~cm}$ de potencia, del cual no se pudo determinar su morfología y dimensiones totales en planta, pues se adentraba más allá de los límites laterales de la propia zanja. Pese a ello, la naturaleza del registro cerámico que se insertaba en dicho estrato no ha dejado dudas con respecto a la relación funcional del mismo con un área de ver- tidos o testar de una figlina, debido a la homogeneidad de los objetos y la presencia, como hemos mencionado, de escorias y desechos de alfar.

En lo concerniente al estudio de estas cerámicas, la bolsada integraba un total de 379 fragmentos, de los cuales entre otros, 128 fueron fallos de cocción de ánforas (32,4\%), 24 escorias de adobe (9\%), 67 fragmentos diagnosticables de ánforas (17\%), 152 individuos eran galbos inconexos de envases anfóricos (38,5\%), 3 tégulas $(0,6 \%), 2$ ímbrices $(0,5 \%)$ y 8 fragmentos de cerámica común (2\%). Del conjunto material hay que destacar la presencia de gran cantidad de fallos de cocción, en los cuales en buena parte se evidencian soldaduras de diversos individuos anfóricos (Figura 3.1, 2 y 3), con alabeados, agrietamientos internos, cavernas de aire y vesículas de escoriación evidentes (Figura 3.4, 5, y 6). De igual forma, también se han individualizado escorias de adobes (Figura 3.7) que deben ponerse en relación con restos fundidos procedentes de alguna estructura de combustión -horno-. Desconocemos la procedencia funcional de estos elementos, pues en ninguno de los individuos se visualizan aspectos específicos relacionados con algunas de las partes en las que se suelen dividir estas piroestructuras. Son objetos de escaso tamaño (entre 8 y $12 \mathrm{~cm}$ ) de morfología diversa y reducido peso que se corresponden con pellas que quizás pudieron haber sido utilizadas como parte de la parrilla del horno (Figura 3.8 y 9). En los hornos de cronología romana el uso del adobe en este foco de producción que es la bahía de Cádiz no suele ser habitual para el alzado de las paredes, donde se usan por un lado los restos de cerámicas desechadas (galbos anfóricos) o material de construcción (ladrillos), estando normalmente el uso de adobes restringido para la confección de la parrilla. Sin embargo, por no tener mayores evidencias al respecto, no podemos asociar con seguridad estos fragmentos a esta parte del horno, no pudiendo descartar su asociación con otras zonas como, por ejemplo, formando parte del enfoscado o revestimiento de las paredes de dicha estructura.

En cuanto al material cerámico, destaca sobremanera la documentación casi en exclusiva de dos tipos anfóricos como son las Dressel 7/11 y las Beltrán II. De ambos tipos también hay individuos sobrecocidos aunque comercializables (figura 3.10 y 11), dando la impresión de que ambos son los envases que se manufacturaron en el taller. Los ejemplares de Dressel 7/11 (Figura 4.1-4) presen- 

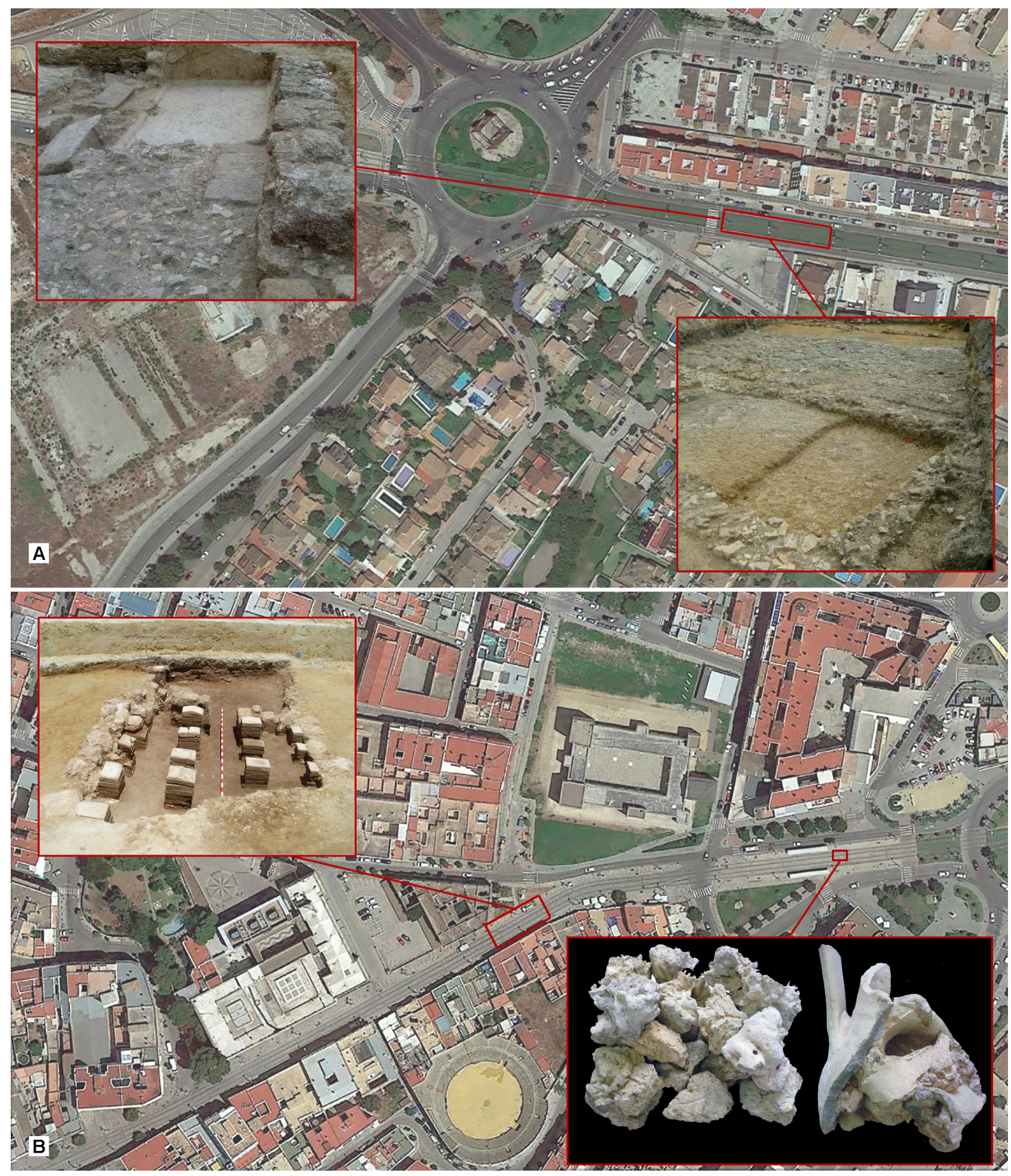

Figura 2. a) Vista aérea de San Fernando a la altura de la Avenida Gómez Pablo con la señalización del emplazamiento de los restos de un asentamiento romano del cual se documentaron diversas estancias y algunas estructuras hidráulicas; b) vista aérea de San Fernando a la altura del Castillo de San Romuado con la señalización de la ubicación de las zonas de estudio, el balneum y el área de vertederos del alfar. 


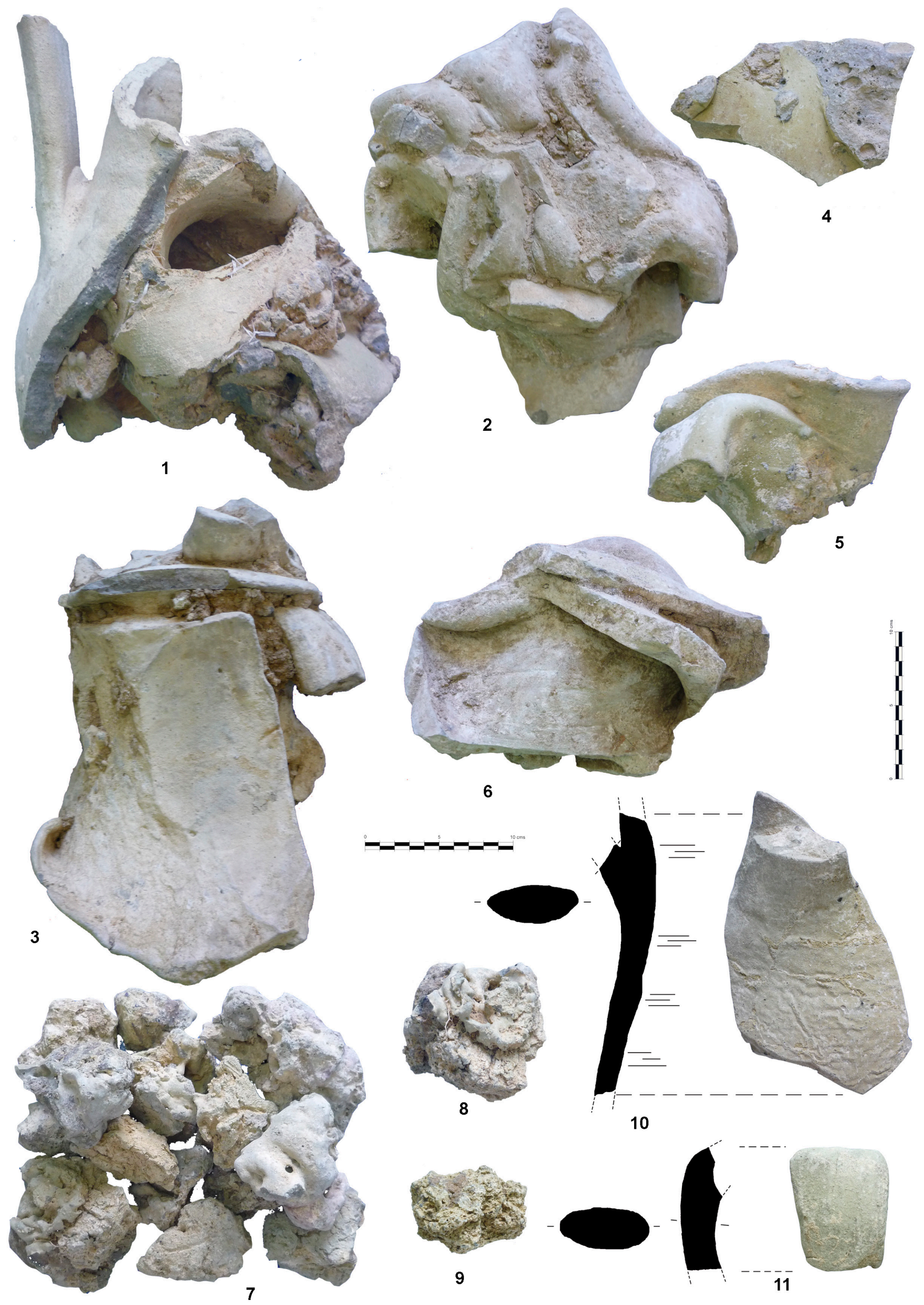

Figura 3. Producciones fallidas de ánforas (1-6); escorias (7); adobes escorificados (8 y 9); asas de ánforas Dressel 7/11 y Beltrán II sobrecocidas (10 y 11).

Revista Atlántica-Mediterránea de Prehistoria y Arqueología Social 22, pp. 229-243 


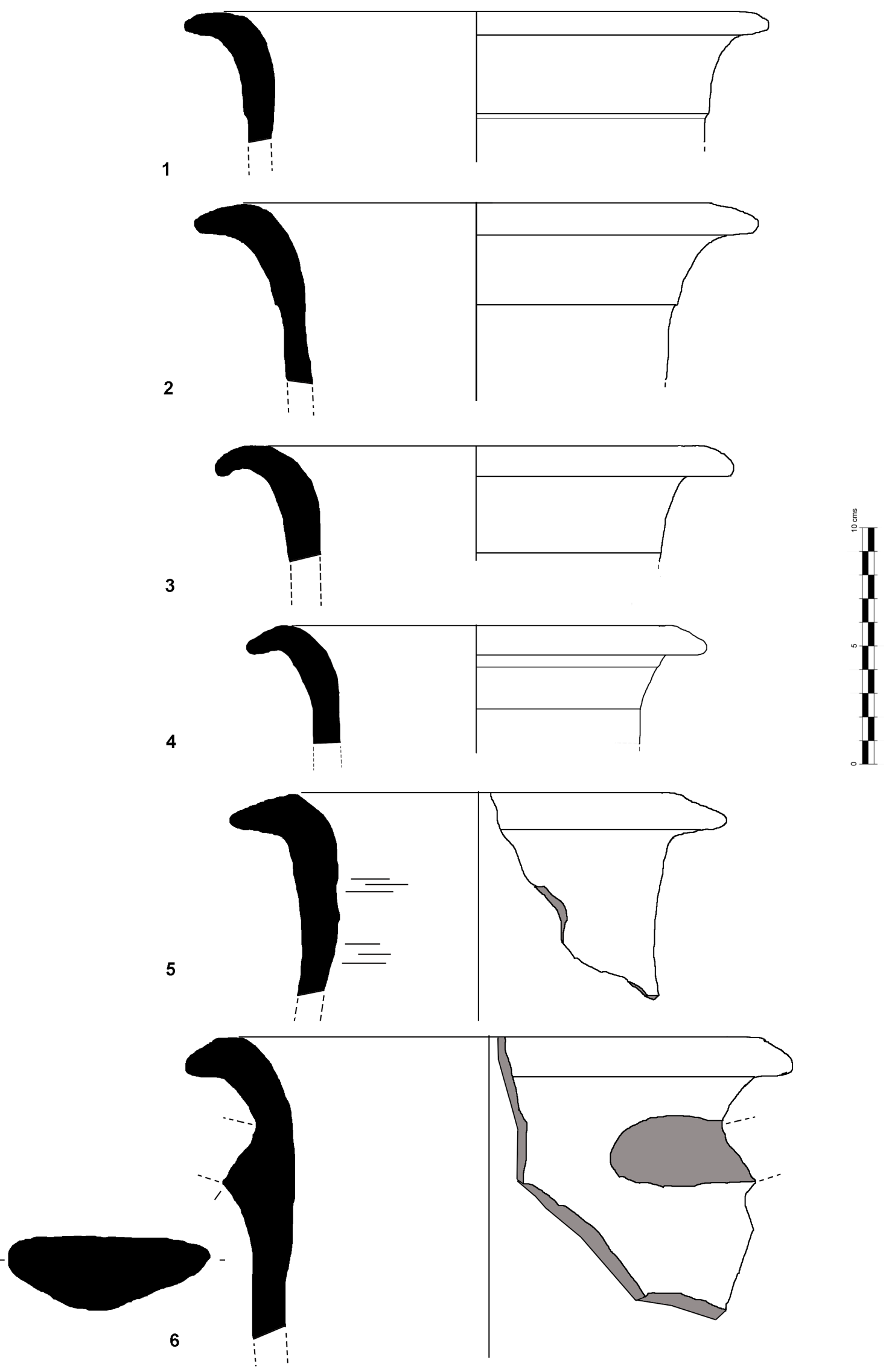

Figura 4. Bordes de ánforas Dr. 7/11 evolucionadas (1-4) y posibles Beltrán II B, variante A (5 y 6). 
tan el borde desarrollado y exvasado al exterior con la carena inferior, característica de este modelo, muy poco acusada. Son individuos evolucionados que bien podrían entenderse como germen de las posteriores Beltrán IIB A, que como hemos dicho, convivieron durante el periodo de actividad de la figlina. Por su parte, parecen identificarse asimismo algunos bordes de Beltrán IIB arcaicas (Figura 4.5 y 6), de sección triangular poco acusada, con una pestaña que no es tan descendente como en otros modelos más canónicos. En el único ejemplar en el que aparece borde y asa, ambas partes aparecen separadas (Figura 4.6). Debemos tener presente que los estadios iniciales de las Beltrán IIB son muy cercanos tipológicamente a las llamadas Dressel 11, por lo que la ausencia de ejemplares más completos no permite definir con mayores precisiones los tipos fabricados en este taller, todos ellos relacionables con las ánforas salsarias de momentos avanzados del s. I d.C.

Completan el registro de esta bolsada, perteneciente al área de vertidos de un taller alfarero, varios fragmentos de cerámica común entre los que destacan algunos bordes de formas abiertas -entre ellos un mortero-, un fondo plano y otro de pie indicado correspondiente a sendos cuencos de cerámica común. Por último, en la interfaz superior del estrato se documentaron dos fragmentos de cerámica vidriada de época moderna que deben corresponderse con los intensos procesos postdeposicionales acaecidos en este espacio situado en el entorno del Castillo de San Romualdo.

Para finalizar con el análisis del vertedero del taller alfarero, y aunque reconocemos la parcialidad del registro, por los datos existentes por el momento podemos vincular el periodo de actividad de este nuevo taller documentado en San Fernando a un periodo comprendido entre las décadas centrales del s. I d.C. y el inicio del periodo flavio. Se trataría por tanto de un taller en principio de escaso desarrollo productivo que estuvo enfocado a la manufactura de contenedores anfóricos salazoneros en un momento en el que, aún dentro del periodo de máximo apogeo de esta industria en la bahía de Cádiz, se estaba observando ya el inicio de un proceso de retroceso, el cual se evidencia sobre todo a partir de finales del s. I d.C. y comienzos de la centuria siguiente, cuando muchos de los talleres alfareros que estaban activos en momentos precedentes (como es el caso de estudio) cesan su producción.

\section{El balneum de la plaza Font de Mora}

A escasamente algo más de cien metros de distancia con respecto a la localización anterior se documentaron en un estado avanzado de arrasamiento una serie de estructuras inmuebles datadas en época romana. Los restos en concreto se situaron entre los PPKK 3+035 y 3+050 de la obra, al noroeste del Castillo de San Romualdo, en el comienzo de la C/ Real a la altura de la Plaza Font de Mora. Durante los trabajos de seguimiento arqueológico se documentaron tres estructuras: una escalera, un pavimento y los restos de la infraestructura de un balneum (Figura 5a).

Sobre la estructura escalonada (Figura 5b), mencionar cómo de ésta se conservaban cuatro peldaños realizados con sillares de piedra ostionera. Por la disposición y morfología de esos sillares, la zona documentada debe vincularse con un ángulo de la misma, incluyendo además un posible cierre lateral realizado también con sillares de ostionera. Inmediatos a esta escalera en la cota superior se conservaban restos de un estrato de tonalidad marrón - anaranjada con pequeños guijarros que bien podría tratarse de una superficie pavimentada. Debido a la parcialidad del registro es difícil posicionarse sobre una posible funcionalidad de estos elementos estructurales, si bien pensamos que, tanto por su factura, disposición, cota, etc... debió formar parte del complejo balnerario que se construyó en época romana en este espacio; sirviendo entonces la escalera para comunicar dos estancias que se encontrarían a diferente cota, como por ejemplo podrían ser el área de calderas con respecto a la superficie de uso.

En cuanto al registro cerámico asociado a esta estructura, hay que decir que su afección por niveles de destrucción de época moderna favoreció la presencia de cerámicas de esa época (lebrillos vidriados, algunos con decoración incisa, vidriados azules sobre blanco o melados,...), si bien de forma mayoritaria se pudieron individualizar restos cerámicos en su mayoría de época romana. Los materiales de época moderna debemos asociarlos con los procesos postdeposicionales desarrollados en la zona en esos momentos en los cuales esta zona sufrió una profunda transformación, motivada por la ubicación cercana del llamado Camino del Arrecife y los procesos urbanísticos y de configuración espacial de la C/ Real que llevaron aparejada la construcción de algunos inmuebles como ejemplifican los casos de las fincas C/ Real 


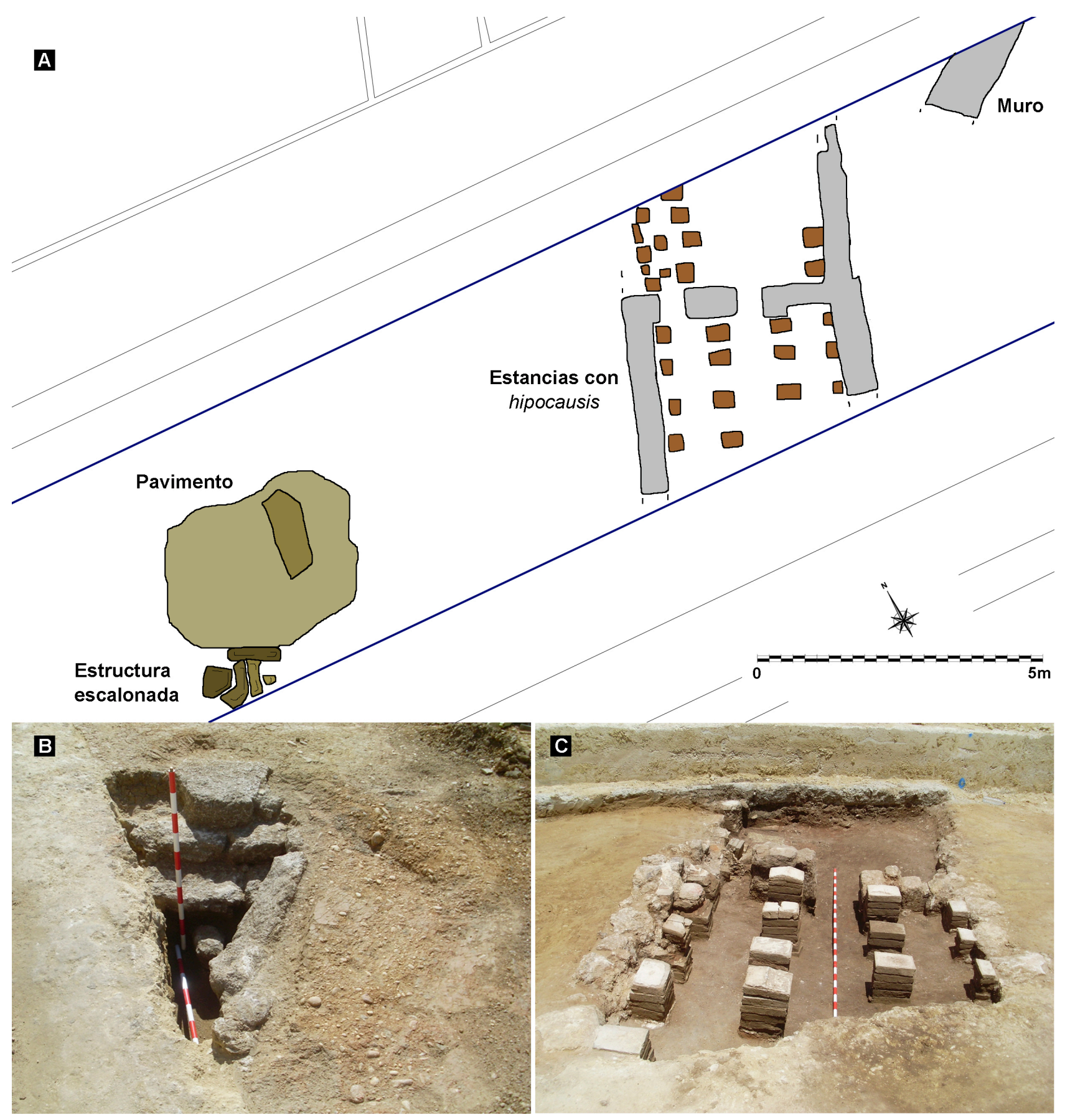

Figura 5. Planimetría esquemática de los restos documentados del balneum (A), con detalle fotográfico de la estructura escalonada (B) y de los restos de las hipocausis (C).

no 1 o C/ Real no 21-23 situadas en las inmediaciones. Por su parte, las cerámicas romanas abarcan un espectro cronológico amplio entre mediados del s. I d.C. y el s. III d.C. En cuanto a la vajilla fina sólo se documentó un ejemplar de reducido tamaño que se corresponde con un galbo de TSG, procedente de los niveles inferiores de la estructura escalonada. Le acompañan en ese nivel algunas asas de jarras / jarritas de cerámica común, un asa de ánfora Dressel 20, un ladrillo de terma y una tégu- la. Colmatando la posible escalera, además de formas abiertas y cerradas de cerámica común o un borde de jarra trilobulada también en común, se localizaron algunos fragmentos anfóricos entre los que merece especial atención la presencia de tres bordes de Beltrán IIA, dos bordes de Beltrán IIB y un borde de Keay XVI. Este último individuo junto con un ánfora africana de pasta rojiza son los que posibilitan retrotraer el proceso de colmatación de la estructura a inicios de época tardorromana. 
Con respecto a los materiales cerámicos aparecidos en torno al posible pavimento, hay que mencionar que el estrato de cubrición se encontraba de nuevo muy afectado por la disposición de las capas superiores de época posterior. No en balde del exiguo elenco cerámico documentado -apenas cinco fragmentos- tres pertenecen a cerámicas de época moderna, siendo los dos restantes un borde de ánfora Beltrán IIA y un borde de una forma abierta (cuenco) de cerámica común. La aparición conjunta de productos cerámicos de cronología tan dispar dificulta la precisión del momento de abandono de esta solería, si bien pensamos que debe coincidir con la cronología general del área.

Apenas a cinco metros al este de estos restos se pudieron excavar parcialmente dos estancias -muy mal conservadas- asociadas funcionalmente con la infraestructura de un balneum (Figura 5c) De ellas sólo se conservaban el arranque del alzado del cierre perimetral, así como de los elementos constructivos hallados en el interior. Se corresponde con los hipocausta de dos salas pertenecientes a unos baños de carácter rural que se construyeron en este asentamiento romano emplazado en el entorno del Castillo de San Romualdo. Sus dimensiones totales se desconocen pues la excavación se restringió a la zona afectada por la ejecución de una zanja, estando incluso gran parte de los restos arqueológicos por debajo de la cota de afección de la obra, si bien por la importancia del hallazgo arqueológico se pudo intervenir sobre ellos y documentarlos. Espacialmente las dos salas se configuran como sendas áreas rectangulares con una orientación relativa noreste-suroeste que se disponen una tras otra, con un muro divisorio común en el que incluso se abren dos vanos de comunicación. La situada en el extremo suroeste es la mejor conocida. De ésta se conocen tres de los cuatro muros perimetrales, extendiéndose hacia el suroeste sin haberse podido llegar a conocer la dimensión real del espacio. Los muros están realizados con sillarejos de ostionera entremezclados con arcilla. Al formar parte de la infraestructura del balneum las unidades constructivas se insertaron en el contorno de una fosa realizada sobre las arcillas del terreno, de ahí que la cara externa de esos tres muros realmente no fuese cara vista, sino que se apoya sobre las arcillas que habían sido recortadas por la fosa de construcción. En el espacio interno se construyeron una serie de pilares a través de la superposición de ladrillos rectangulares. Estos pilares estaban dispuestos de forma ordena- da con al menos cinco filas con cuatro pilares cada una. Los de los extremos estaban adosados a la cara interna de los muros perimetrales, mientras que los otros dos se dispusieron de forma equidistante en el espacio interno que restaba. Del segundo, apenas se excavó una cuña muy exigua por lo que el conocimiento es menor. En este sentido, el muro perimetral noroeste no se conservaba, y de las filas y pilares apenas se mantenían algunos arranques en los laterales, habiéndose perdido por completo cualquier rastro de la hilera de pilas de la parte central. Algunos de estos pilares mostraban restos de haber sufrido algún tipo de termoalteración, lo que favorece la hipótesis de que estos dos espacios deban asociarse con la infraestructura hipocáustica de unos baños rurales. Así, los pilares debieron funcionar como suspensura o elementos sustentantes de un suelo o pavimento de una sala calefactada, ya fuera el caldarium o el tepidarium, pudiendo -ipor qué no?- haber funcionado como sudatio o sala de calor seco. En este tipo de construcciones solía ser habitual que desde esos pilares se desarrollasen arcadas por aproximación de ladrillos, dando mayor estabilidad al suelo que sostuvieron (García-Entero, 2006). Sin embargo, debido a la escasa altura conservada de dichos pilares no se apreciaban restos de esos posibles arcos.

Entre el material recuperado se han podido individualizar algunos ladrillos con apéndices en positivo y negativo (Figura. 6.1 y 2), un ladrillo con decoración romboidal digitada, así como un ladrillo de sección rectangular (figura 6.3) que bien podría haber servido como elemento del sistema de canalización del calor desde la infraestructura hasta la sala de uso. De nuevo constatamos la presencia de cerámicas de época moderna e incluso algunas piedras de chispa producto todo ello de la afección de las estructuras de época romana en esos momentos posteriores. Son fragmentos asociados con botellas de vidrio, jarras, lebrillos $\mathrm{u}$ otras formas que aparecen decoradas con vedríos melados. Con respecto al material cerámico de época romana los fragmentos diagnosticados abarcan un periodo cronológico situado entre mediados del s. I d.C. y época tardorromana. Sobre las ánforas destaca la presencia de algunos bordes, asas y pivotes huecos (Figura 7.2 y 3 ) de ánforas salsarias altoimperiales como son las Beltrán IIA (Figura 7.1), que deben proceder del alfar cercano, puesto que incluso en estos contextos también han aparecido algunos defectos de cocción (Figura 

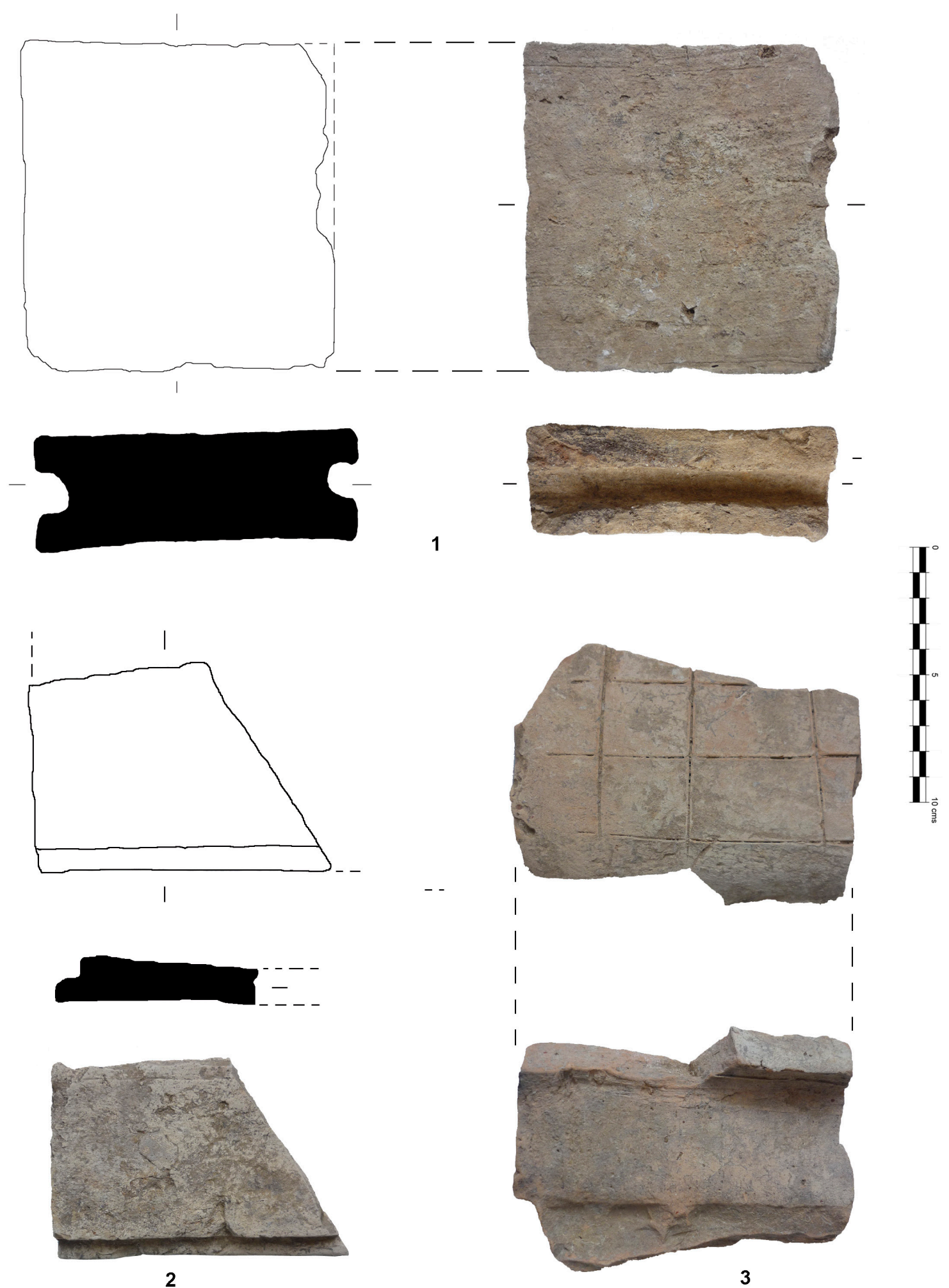

2

3

Figura 6. Ladrillos de termas con escotaduras (1 y 2) y elemento latericio hueco, con sección rectangular (3). 

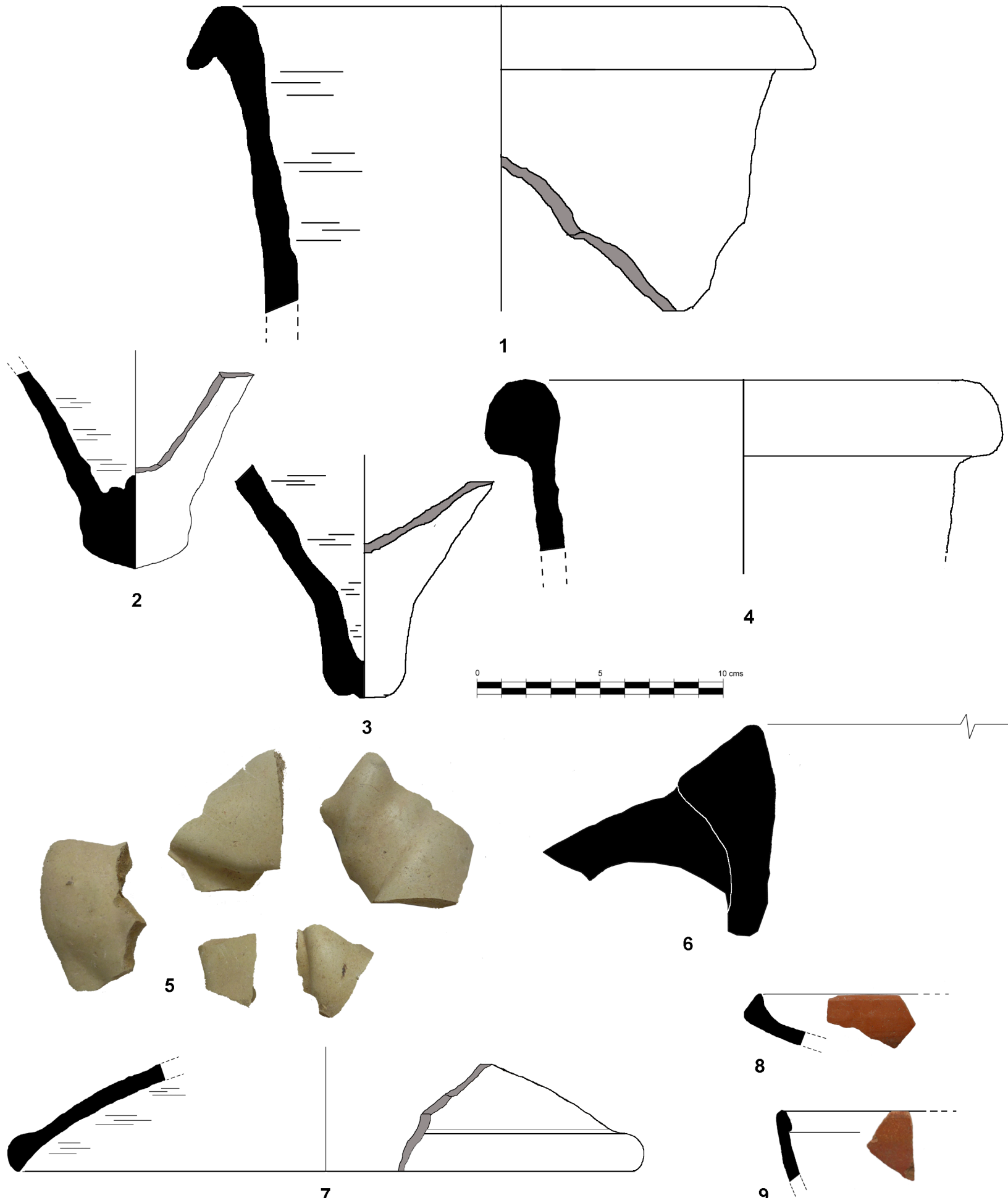

8

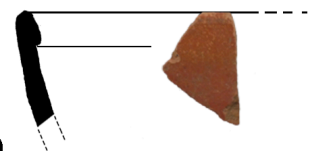

Figura 7. Borde de ánfora Beltrán IIA (1); pivote de ánforas salsarias béticas (2-3); borde de posible Dressel 14 (4); fragmentos de ánforas vitrificados (5); borde de Puerto Real 1/2 o Keay XVI (6); borde de Hayes 196 en africana de cocina (7); borde de Hayes 61 en ARSW D (8); borde de Hayes 23 B en africana de cocina (9).

Revista Atlántica-Mediterránea de Prehistoria y Arqueología Social 22, pp. 229-243 
7.5). También hay otras ánforas como ejemplifica el borde de una posible Dressel 14 (Figura 7.4). De época posterior serían algunos pivotes rellenos, así como algunos bordes de ánforas entre los que destaca uno perteneciente a una Puerto Real $1 / 2$ o Keay XVI (Figura 7.6). En los niveles de relleno de la estructura no sólo se documentaron fragmentos anfóricos, sino que también había presencia de vajilla fina y cerámicas comunes o de cocina. En este último caso, aparece un borde de una tapadera de africana de cocina del tipo Hayes 196 (Figura 7.7). Hay también bordes de lebrillo de cerámica común, así como otras formas abiertas y cerradas. En cuanto a vajilla fina, además de un galbo en ARSW D, se han podido individualizar un borde en ARSW D de la forma Hayes 61 (Figura 7.8) y un borde engrosado al interior muy fragmentario de una Hayes 23B en africana de cocina (Figura 7.9). El arco cronológico del abandono de la zona presenta evidencias claras de momentos medio imperiales, prolongables hasta finales del s. IV o inicios del $V$ por las citadas formas de sigilata clara de la producción D.

Para finalizar el análisis de este espacio termal, a unos 10-15 m de distancia con respecto al balneum se documentó un área de dispersión de materiales en el que se documentaron, además de una asa de una jarra y un borde de un lebrillo, un borde y asa de ánfora salsaria bética (Dr. 7/11) y un cuello entero de este tipo anfórico (Figura 8). Como dato destacable, este fragmento presentaba un sello cuadrangular en el cuello, si bien el estado de conservación impedía hacer una lectura clara del contenido. Es un tipo de sello que no suele ser habitual en este modelo anfórico, habiendo encontrado un posible paralelo en un ejemplar documentado en Sala (Rabat, Marruecos) donde la marca también se encuentra en el cuello, y cuya lectura se ha interpretado como P. L( ) E( ) con la "p" y la "l" ligadas (Boubé, 1973-1975, 168, no 2, fig. 1.2).

\section{Valoración general de los hallazgos}

La localización de elementos de época romana en el entorno del Castillo de San Romualdo, aunque exiguos, se retrotrae a finales de la década de los ochenta, cuando en 1987 R. Corzo practicó una cata en una de las torres. El control arqueológico de una zanja para la conducción de cableado de telecomunicaciones en 1991 por parte de A. Sáez Espligares también propició la recuperación de otra serie de materiales de época romana junto a otros de épocas posteriores -medievales y modernos-. El estudio de ambos conjuntos fue publicado por J.A. Ruiz Gil (1994), quién individualizó un fragmento de T.S.H. decorada y varios fragmentos de cerámica común. Posteriormente, cuando comenzaron los estudios arqueológicos en la fortaleza tras su expropiación y el inicio del proyecto de consolidación y restauración, la documentación de productos arqueológicos asociados con este periodo se ha multiplicado, lo que evidencia cada vez con mayor fuerza la existencia de "...una pequeña aglomeración rural, a una villa de considerables proporciones o quizá a una turris o castellum de corte defensivo..." con un largo lapso de perduración entre época republicana y el s. VI d.C. (Sáez et al., 2009: 926). De todos los hallazgos quizás es destacable la documentación de una posible área de necrópolis que evidenciaría la existencia de una zona de hábitat estable, así como de materiales cerámicos recuperados del relleno interno del foso del castillo, aunque minoritarios con respecto a los de época medieval. Entre ese material romano destaca la mayoritaria presencia de ánforas Beltrán II A-B, así como Dressel 7/11 e incluso algunas formas de ánforas Puerto Real 2, así como restos de tegulae, alguna sigilata hispánica y ánforas de importación africana (Keay XXV...) (Sáez et al., 2004: 108).

A estos hallazgos hay que sumarle los documentados gracias al control arqueológico desarrollado con motivo de la construcción del Tranvía Metropolitano de la Bahía a su paso por San Fernando que, como hemos podido observar en estas páginas, ha permitido realizar una propuesta funcional y cronológica al asentamiento. Así, la existencia de un área de baños privados ejemplificado en los restos de dos hipocausta de sendas salas termales, nos habla de un asentamiento de cierta importancia. De igual forma, esta aglomeración tendría asociada en los primeros momentos de vida de la misma un área de trabajo relacionado con la fabricación de envases anfóricos, tal y como ha quedado demostrado con la localización parcial del área de vertidos del taller cerámico.

La existencia de asentamientos rurales con alfar anexo es un modelo que se viene repitiendo en San Fernando -la posible Antipolis estrabonianacomo se desprende de diversos yacimientos romanos como pueden ser Cerro de la Batería, Gallineras - Cerro de los Mártires, etc... (Bernal-Casasola et al., 2005; Díaz et al., 2017). Incluso en el entorno del Castillo de San Romualdo ya se habían docu- 
De la ocupación romana en Ad Pontem: evidencias de las obras del tranvía metropolitano junto al Castillo de San Romualdo (San Fernando, Cádiz)

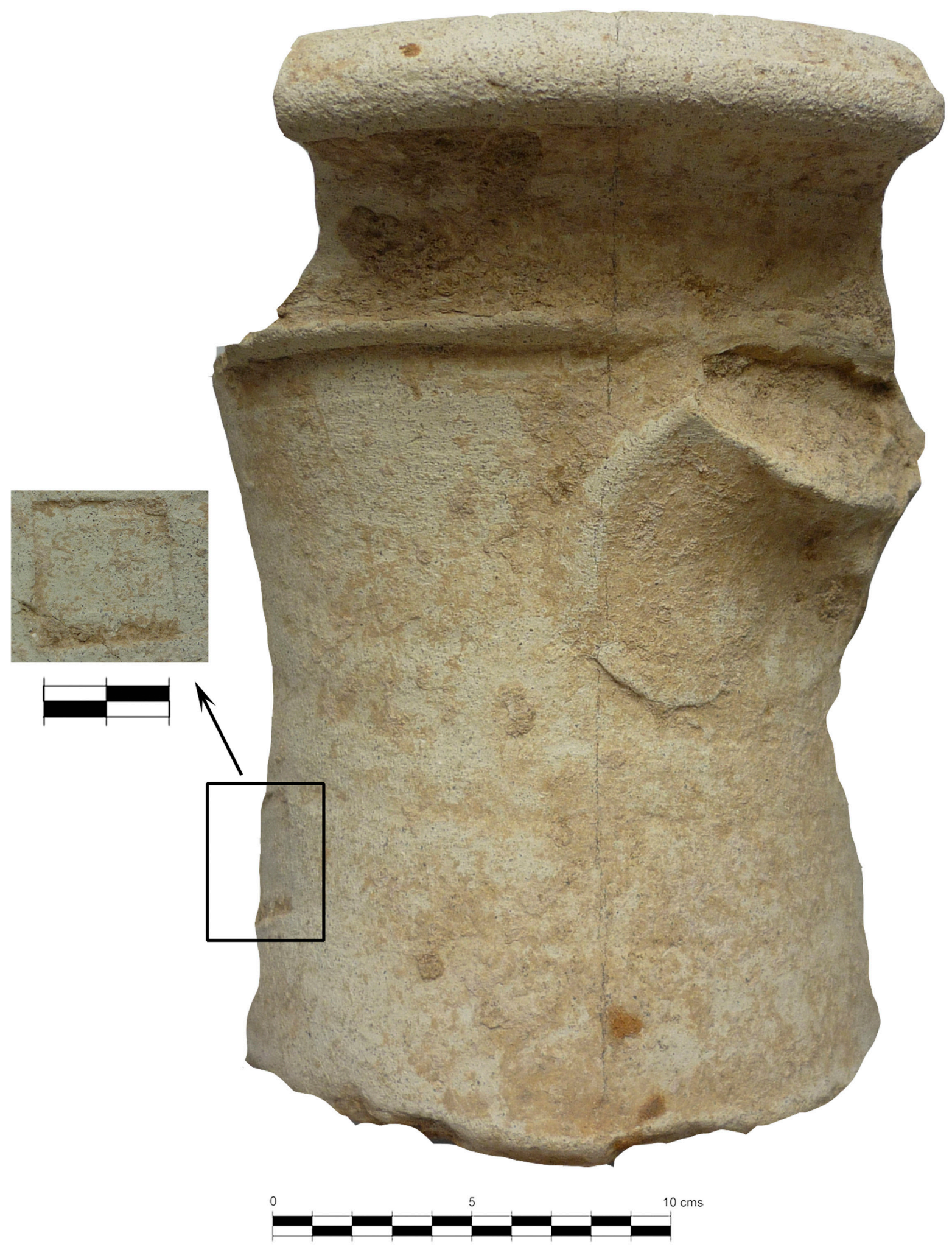

Figura 8. Dressel 7/11 con sello cuadrangular de compleja lectura ¿P.L( ) E ( )?, en cartela cuadrangular.

Revista Atlántica-Mediterránea de Prehistoria y Arqueología Social 122, pp. 229-243 
mentado evidencias alfareras y un enterramiento en el denominado alfar de C/ Albardonero - C/ San Servando, con un periodo de actividad centrado entre el s. II y III d.C. (Díaz et al., 2004; Sáez y Díaz, 2010: 316; Sáez y Sáez, 2004).

La constatación de todos estos vestigios debe responder a la presencia de un posible foco de poblamiento en el entorno del puente Zuazo, donde debemos emplazar a la mansio Ad Pontem (Rambaud, 1977) citada tanto en el Anónimo de Rávena como en el Itinerario Antonino $(409,2)$. El paso hacia Gades cruzando el río Arillo debió tener un puente para salvar este paso de agua. Lo mismo le ocurriría al acueducto cuyo trazado iba en paralelo a la via augusta (Pérez y Bestué, 2010). Controlar dicho paso, así como establecer un punto de descanso, aguada o refugio previo a la llegada a Gades pudo ser una de las razones de la existencia de esta mansio, una aglomeración secundaria similar a los vici o pagi que junto a otras mansiones como Ad Herculem y las villae rústicas fueron los modelos de asentamiento desarrollados en el territorium de la urbs gaditana (Bernal-Casasola, 2008). Con ello se explicaría la dispersión de los hallazgos aparecidos, cercanos pero no aglomerados; un fenómeno propio de las instalaciones rurales en las cuales no hay presión urbanística, lo cual provoca, entre otros aspectos, el espaciado de sus instalaciones. Y también permiten, indirectamente, verificar que el trazado de la via en dirección a Gades no discurría exactamente en esta zona por la posterior calle Real, ya que bajo ella se han localizado estos restos romanos de época alto y medio imperial.

Siguiendo esta hipótesis de trabajo, las evidencias arqueológicas (alfar y balneum) aquí analizadas no son más que un fiel refrendo de la importancia tanto estratégica, como económica (actividades productivas que indirectamente nos hablan de la industria pesquero-conservera, al tratarse de ánforas salazoneras) y social (existencia de baños privados) que esta zona situada alrededor del Puente Zuazo -y por ende del acueductoalcanzó durante un amplio periodo cronológico que, para los hallazgos arqueológicos aquí analizados, se circunscribirían a un momento situado entre mediados del s. I d.C. y finales del s. IV o inicios del V d.C.

Las evidencias romanas en el entorno del Castillo de San Romualdo son, por el momento, sutiles y su grado de conservación exiguo, pero ello no quita para que, al igual que siempre nos ha demos- trado Antonio Sáez Espligares, mantengamos la esperanza de que en un futuro próximo salgan a la luz nuevas evidencias que pongan de relieve la significancia que debió haber ostentado la mansio Ad Pontem en la Antigüedad, un lugar de paso y tránsito continuo $\mathrm{y}$, al mismo tiempo, un ambiente productivo volcado a la explotación de los recursos marinos y salineros especialmente.

\section{Agradecimientos}

Este trabajo es resultado y ha sido cofinanciado por el proyecto "ARQ-ANALYTICs. Analíticas y Nuevas Tecnologías aplicadas a la Arqueología de la producción de las sociedades marítimas púnico-romanas en la Bahía de Cádiz (CEIJ-C03.1)" de la Convocatoria de ayudas a proyectos de investigación "Jóvenes Investigadores CEI·MAR 2019", así como por el proyecto GARVM III (PID2019108948RB-I00/ AEI / 10.13039/501100011033) del Gobierno de España/Feder; por el Programa Operativo FEDER 2014-2020 y por la Consejería de Transformación Económica, Industria, Conocimiento y Universidades de la Junta de Andalucía (referencia del proyecto: ARQUEOSTRA, FEDER-UCA18-104415); y por el proyecto ARQUEOFISH (P18-FR-1483) del Programa de Ayudas a la I+D+i del Plan Andaluz de Investigación, Desarrollo e Innovación (PAIDI 2020).

\section{Bibliografía}

BERNAL-CASASOLA, Darío. 2008: “Gades y su bahía en la Antigüedad. Reflexiones geoarqueológicas y asignaturas pendientes". Revista Atlántica-Mediterránea de Prehistoria y Arqueología Social, 10, pp. 267-308.

BERNAL-CASASOLA, Darío; SÁEZ ESPLIGARES, Antonio; SÁEZ ROMERO, Antonio Manuel; DÍAZ RODRÍGUEZ, José Juan; LORENZO MARTÍNEZ, Lourdes. 2005: Carta Arqueológica Municipal de San Fernando (Cádiz). Consejería de Cultura de la Junta de Andalucía. Sevilla.

BOUBÉ, Jean. 1973-1975: "Marques d'amphores découverts à Sala, Volubilis et Banasa". Bulletin d'Archeologie Marocaine, IX, pp. 163-235.

DÍAZ RODRÍGUEZ, José Juan; SÁEZ ROMERO, Antonio Manuel; MONTERO FERNÁNDEZ, Roberto; MONTERO FERNÁNDEZ, Anabel. 2004: "Alfarería romana en San Fernando (Cádiz). Análisis del proceso productivo cerámico en el hinterland insular de Gades". En D. BERNAL 
y L. LAGÓSTENA (eds.): Figlinae Baeticae. Talleres alfareros y producciones cerámicas en la Bética romana (ss. II a.C.- VII d.C.), pp. 649662. BAR International Series. Oxford.

DÍAZ RODRÍGUEZ, José Juan; SÁEZ ROMERO, Antonio Manuel; SÁEZ ESPLIGARES, Antonio. 2017: “Gallineras - Cerro de los Mártires (San Fernando)”. En R. HIDALGO (ed.): Las villas romanas de la Bética, vol. II, pp. 94-106. Editorial de la Universidad de Sevilla. Sevilla.

GARCÍA-ENTERO, Virginia. 2006: Los balnea domésticos, ámbito rural y urbano, en la Hispania romana. Colección Anejos de Archivo Español de Arqueología. CSIC. Madrid.

LAVADO FLORIDO, María Luisa. 2011: "Arqueología preventiva y construcción de la Historia local: la intervención arqueológica desarrollada con motivo de la construcción del tranvía urbano (2009-2010)". En E. VIJANDE, J.J. DÍAZ y A.M. SÁEZ (coords.): Historia y Arqueología en la primera década del s. XXI en San Fernando, II Foro sobre Arqueología de San Fernando (Cádiz), pp. 28-29. San Fernando.

LAVADO FLORIDO, María Luisa; SÁEZ ROMERO, Antonio Manuel. 2009: "Una nueva área alfarera de Gadir". Boletín de la Sociedad de Estudios de la Cerámica Antigua en Hispania, 1, pp. 12-13.

PÉREZ MARRERO, Jenny; BESTUÉ CARDIEL, Isabel. 2010: "Nuevas aportaciones al estudio hidráulico del acueducto romano de Tempul". En L. LAGÓSTENA, J.L. CAÑIZAR y Ll. PONS, (eds.): Aqvam Perdvcendam Cvravit. Captación, uso y administración del agua en las ciudades de la Bética y el occidente romano, pp. 183-196. Servicio de Publicaciones de la Universidad de Cádiz. Cádiz.

RAMBAUD, François. 1977: "Portus Gaditanus". Madrider Mitteilungen, 38, pp. 75-88.

RUIZ GIL, José Antonio. 1994: "Los orígenes de San Fernando: una aportación desde el Castillo de San Romualdo". Actas de los X Encuentros de Historia y Arqueología, pp. 87-95. Fundación Municipal de Cultura de San Fernando. San Fernando.
SÁEZ ESPLIGARES, Antonio; TORRES LÁZARO, Julio; SÁEZ ROMERO, Antonio Manuel. 2009: "Monedas bajomedievales del Castillo de La Puente (San Fernando, Cádiz). Aportaciones a los orígenes y evolución de la fortaleza". En A. ARÉVALO (ed.): Actas del XIII Congreso Nacional de Numismática Moneda y Arqueología, Tomo II, pp. 923-949. Servicio de Publicaciones de la Universidad de Cádiz. Cádiz.

SÁEZ ROMERO, Antonio Manuel; DÍAZ RODRÍGUEZ, José Juan. 2010: “La otra necrópolis de Gadir/Gades. Enterramientos asociados a talleres alfareros en su hinterland insular". En A.M. NIVEAU y V. GÓMEZ (coords.): Las necrópolis de Cádiz. Apuntes de arqueología gaditana en homenaje a J.F. Sibón Olano, pp. 251-337. Diputación de Cádiz y Servicio de Publicaciones de la Universidad de Cádiz. Cádiz.

SÁEZ ROMERO, Antonio Manuel; MONTERO FERNÁNDEZ, Roberto: MONTERO FERNÁNDEZ, Anabel; SÁEZ ESPLIGARES, Antonio; DÍAZ RODRÍGUEZ, José Juan. 2004: "Anotaciones al recorrido de las vías Augusta y Heraclea a su paso por San Fernando (Cádiz). Novedades arqueológicas y paleogeográficas". Antiquitas, 16, pp. 105-119.

SÁEZ ROMERO, Antonio Manuel; SÁEZ ESPLIGARES, Antonio. 2004: "Control arqueológico de urgencia realizado en el solar ubicado en c/ Albardonero 24 (San Fernando, Cádiz). Anuario Arqueológico de Andalucía. Tomo III, pp. 93-98. 